that I collected statistics of operations in all stages of the disease ${ }^{2}$ published from 1891 to 1908, and found that during that period lumbar nephrectomy for tuberculous disease gave a mortality of 27.4 per cent. and abdominal nephrectomy 33 per cent. Now we find that when the disease is limited to one side and there is no tuberculous disease elsewhere, nephrectomy results in cure in 30 per cent., with an operative mortality of about 10 per cent. This is taking general statistics, but in the hands of surgeons of great experience the cures are in a larger proportion, and the mortality is about one-half-namely, 5.8 per cent. I may now take Walker's statistics, ${ }^{3}$ giving the remote results in 210 cases of nephrectomy: Reported as well, 79 cases; recovered, 83 cases; cured, 20 cases ; good results, 4 cases; improved, 7 cases; not improved, 2 cases ; improvement not maintained, 15 cases. I think it will be admitted that these statistics convey a different impression from that contained in the remarks made in Dr. West's address.

Further, Dr. West says, "When the disease in one kidney is advanced enough to be capable of certain diaguosis the chances of the otber kidney being affected too are very considerable ......" This depends, of course, upon the methods employed in making the diagnosis and the stage at which the disease is detected, but let that pass, and permit me to quote a passage from Watson and Cunningham ${ }^{i}:-$

Clinical evidence of unilateral renal tuberculous infection.-The testimony of this nature upon the unilateral occurrence of renal tubereulosis is ferived from, and based upon, the examinations of the urines drawn separately from each of the two kidneys, and from the facts with regard to permanency of the cures or entire absence of evidence of the existence of renal tuberculosis subsequent to nephrectomy of the kidney which is known to be invared by it. Upon the evidence of thi character, such surgeons as Kromlein, Israel, Kummel, Rafin, Kelly, Bevan, leynaud, Casper, and Hurry Fenwiek assert that the process at the time at which the patients were examined by them, was confined to one kidney in from 50 to 80 per cent. of the cases.

Or, taking the disease not at the stage when it should be presented to the surgeon, but when it has done its worst and has come under the review of the morbid anatomist rather than the clinical pathologist, Halle and Mot $z^{5}$ found in 131 cases of renal and ureteral tubersulosis examined by them post mortem, in 89 the disease was confined to one side, in 42 it was bilateral.

I think it right to place these facts before the readers of THE LAXCET to justify the position I have maintained thatIt is to the diagnosis of tuberculosis in the early stage that we must aid of the surgeon is of little arail.

And-

In sone instances $x$ hen first seen by him [the surgeon] the disease is so advanced that little can be attempted to stay its progress or to mitigate the suffering of the patient, while in other cases the malad is still limited in extent, and much may be done by early surgical intervention. Even a few rears ago renal tuberculosis was looked upon as almost a certainly fata! maladr, but now that new and more exact methods can be employed in detecting the disease in the early stace, the surgeon is not uncommonly placed in a position to adrise and to carry out operative measures with considerable hope of success.

I am, Sir, yours faithfully,

Glasgow, Dec. 2nd, 1911 DAVID NETYMAT.

\section{A SPHYGMOGRAPHIC METHOD FOR THE ESTIMATION OF SYSTOLIC AND DIASTOLIC BLOOD PRESSURE.}

To the Eaditor of THE LANCET.

Sik.-In Mr. S. G. Longworth's letter in your issue of Dec. 2nd it is stated that "according to Dr. George Oliver and others, the point to take [for the reading of the diastolic pressure] is that at which a distinot change in the intensity of the sound occurs, which is generally pronounced and limited to 1 or $2 \mathrm{~mm}$. of the scale." So far as I am concerned, your correspondent is under a misapprehension. The later results of my observations, which appeared in the Quarteriy Journal of Experimental Physiology, March 3rd, 1911, support the view of Ettinger, Gettings, and others to the effect that the disappearance of the throb on release of airpressure indicates the minimum arterial pressure. I said "If we accept the lower limit of throb as the indicator of the

2 Article, Operations on the lidineys and Ureters, Burghard's Operative Surgery, vol. iii., p. 403.

Quoted by Watson and Cunningham, vol. ii., p. 401.

4 Diseases and Surgery of the Genito-U rinary System, vol. ii., p. 390. xxiv, 161-241.

Surgical Diseases of the Kidney, 1888, p. 295.

ThE Lancel, 1900 , vol, i., p 526. true diastolic or minimum pressure, then the range of throb furnishes three readings of the arterial blood pressurenamely, those of the minimum, the mean, and the maximum pressure. $\ldots$ Observation shows that the mid-reading coincides, as a rule, with the optimum oscillation of the mercurial column, which has hitherto been accepted as the indication of the diastolic pressure. We do not, however, know what the maximum oscillation as an indicator of arterial blood pressure actually does signify, and it is not improbable that further observation will show that it represents more nearly the mean arterial pressure rather than the true diastolic pressure." The diastolic pressure definitely afforded by the disappearance of the throb has not yet been studied and appreciated sufficiently in clinical work

I am, Sir, yours faithfully

Farnham, Dec. 10th, 1911 GEORGE OLIVER.

\section{THE PRACTICE OF MEDICINE IN BRITISH COLUMBIA.}

To the Editor of THE LANCET.

SIR, - As I think considerable misapprehension exists in the British Isles in regards to the conditions of medical practice prevailing here, I venture to call attention to certain facts in the hope that the information may be a help to others. Before I arrived here $I$ was firmly convinced that my Edinburgh qualifications would be sufficient to enable me to practise medicine here. I thought I had merely to hang up a blass plate and the patients would come flocking in. This is, however, not the case. In British Columbia and in Alberta, as I believe in all the provinces in the Duminion of Canada, there is a medical examination. This is open to any medical man or woman who has studied medicine for a minimum of four years at a recognised medical school and obtained his diploma. Nobody is allowed to practise in British Columbia or in Alberta until he or she has passed this examination.

It would appear that almost complete ignorance prevails at home with regard to this examination, and it is entirely erroneous to consider it as anything but a severe test of knowledge. In British Columbia the examination lasts for the better part of two weeks, and papers are set in all the subjects in the average medical course, with the exception of biology and physics. Clinicals and orals are conducted in medicine and surgery, as well as an examination in prac. tical bacteriology and in clinical methods. The examination is a thoroughly fair test of knowledge and is practical, as the examiners are, without exception, either specialists in the subjects in which they examine or general practitioners.

In May there were 42 candidates. of whom 19 failed, and this month 62 made their appearance, and 23 were unsuccessful. In each examination several candidates with qualifications from the British Isles were unsuccessful. In both May and this month an Edinburgh graduate failed to qualify, and two or three London College men were among those rejected. Now these were in every case quite good men, and the reason of their failure was owing to their ignorance of prevailing conditions. They had read or been told that the examination was a mere formality, and had regarded it as such. For my own part I arrived in British Columbia two full months before the examination last May, and devoted the time to reading. Despite this fact, and the experience I had gained as a house physician and surgeon in Edinburgh, I was by no means certain of the result until the lists appeared. In Alberta the conditions are similar, although there are no oral and clinical examinations.

We have here a wonderful country and one that will loom largely in the future history of the world. It is undoubtedly a land of promise, and conditions of practic 3 are very much more favourable than in the British Isles. "Old Country" graduates are always welcome here, not ouly among the general public, but also among our Canadian colleagues, and it seems to me a pity that men who are undo xbtedly skilled practitioners should fail at an examination when a little extra preparation would entirely alter the result.

Although this is in every way a very favourable country in which to practise medicine, money is not made with quite that rapidity which many expect. A certain amount of capital is necessary. In Vancouver, with any reasonable success, $\$ 1500$ should be made in the first year. In the smaller towns and in the Kootenay and the Cariboo fees are 
larger, and most of the doctors make their expenses from the start. In any case practitioners should be prepared to wait for a few months at least, and it would be well if this fact were understood. Then we would not be faced with the spectacle of an " Old Country" graduate arriving with some $\$ 170$ as his entire assets. Even this might be overcome if he succeeded in satisfying his examiners, but in default it means a nearer acquaintance with a pick and shovel or other form of manual labour.

In conclusion, I would say that I shall at any time be delighted to answer any communication I may receive regarding this undoubtedly wonderful country with its endless opportunities.

I am, Sir, yours faithfully,

GEORGE Gibson, M.D., M. R. C.P. Edin.

724, Robeon-street, Vancouver, B.C., Nov. 14th, 1911.

* We may mention, in regard to the above interesting letter, that in an article on "The British Medical Man Abroad" 1 it is stated that an examination has to be passed before a qualified person is admitted to the Register in British Columbia and Alberta.-ED. L.

\section{THE STATISTICS OF THE BENENDEN SANATORIUM.}

To the Editor of THE LAN OET.

SIR, - In a recent publication, "Sanatoria for the People," 2 the authors, Mr. C. H. Garland and Dr. T. D. Lister, have made some very definite statements regarding the results of the treatment of tuberculosis in the Benenden Sanatorium. They state (pp. 16 and 17) that " as a matter of accumulated experience, the successful cases wherein the disease becomes completely arrested are about 70 to 80 per cent. of the admissions," and further that "with patients able and willing to continue their working lives under simple bygienic modifications, 80 per cent. are found to be still on full work and wage-earning two years after discharge; and as knowledge spreads among the working classes, as shown by the German insurance experience, the lasting nature of the recovery tends to increase. Statistical evidence will be found in Appendix II."

I have carefully examined the figures given in Appendix II., and so far as I understand them can find none which appear to provide the above percentages. It is obviously of the highest importance that data in publications of this kind, directly intended to influence public opinion, should be so expressed as to be intelligible to the layman. May I therefore as a layman ask the authors to explain how they reach these percentages?-I am, Sir, yours faithfully,

Galton Eugenics Laboratory, University College, GowerDAVID HERON. street, W.C., Dec. 12th, 1911.

\section{THE PRESCRIPTION OF TUBERCULIN.}

\section{To the Editor of THE LANCET.}

SIR,-Mr. P. W. Squire's memorandum attached to the letter of Sir R. Douglas Powell and Dr. P. Horton-Smith Hartley appears to confuse rather than settle the issue raised by your reviewer. The review stated that instead of representing the small initial dose of T.R. by " $0.000,000,001$ cubic centimetre," "a more convenient method would seem to be to express the amount in fractions of a milligramme." Your reviewer will doubtless make his meaning clear, but workers with tuberculin would understand this to mean valgar fractions of a milligramme of tubercle bacilli, not fractions of a milligramme of T.R. liquid, as assumed by Mr. Squire.

The point raise $d$ by your reviewer is sufficiently important to be illastrated by experience. I have made an examination of the 1000 last orders received by Messrs. Allen and Hanburys for T.R. and B.E. (the two forms of tuberculin to which the alternative method of stating the dose applies), and find that on 912 orders the dose is stated in vulgar fractions of a milligramme of tubercle bacilli, and in 23 cases in decimal fractions of a cubic centimetre of the concentrated liquid. On all Messrs. Allen and Hanburys' labels the

1 The Larcet, Sept. 2nd, 1913, p. 713.
2 The Scientific Press, Limited, 1911. dose is stated in both forms-e.g., "New Tuberculin T.R. $0.000,001$ c.c. $(1 / 100,000$ milligramme T.B. $)$; physicians can therefore employ the system they prefer without trouble. Although precedence is given on the label to the decimal method of stating the dose now used by the makers of Koch's tuberculins, on $91 \cdot 2$ per cent. of the orders received the doses are written in vulgar fractions of a milligramme of tubercle bacilli. I think it must therefore be conceded that the latter is the more popular and presumably the more convenient way. I am, Sir, yours faithfully, F. W. GAMBLE,

Pharmaceutical Chemist ; Examiner to the Pharmaceutical Societv; Manager, Allen and Hanburys, Ltd.

Vere-street, W., Dec. 11th, 1911.

\section{A PLEA FOR AN AMENDED CLASSIFICA- TION OF UTERINE FIBROIDS.}

\section{To the Editor of THE LANCET.}

SIR,-Permit me space to make a suggestion as to the amendment of the usual description of fibroid tumours of the uterus in regard to their position in the uterine wall. Hitherto hard and soft fibromata of the uterine wall have been described as submucous, mural, and subserous. The submucous fibroid is occasionally pedunculated; the subserous is more often so. The foregoing classification was strictly anatomical. What I now propose is a classification which, whilst being anatomical, is in every sense of the term clinical as to pathology and treatment. I will now briefiy explain.

Most uterine fibroids are placed either inside or outside the centre of the middle coat, which is occupied by the larger blood-vessels supplying the uterine wall. The classification I now propose is to locate every nterine fibroid, anatomically and clinically, either on the inner or the outer aspect of the central vascular zone of the middle coat. Anatomically, therefore, one would speak of an "inner" and an "outer"; fibroid, sessile or pedunculated, in strict $r \in$ lation to the central vascular zone of the middle coat of the uterus, because this classification, from a clinical point of view, can be shown to be important. I have so often seen a uterus which is the subject of multiple fibroids have all of them confined either to the inner or the outer side of this vascular zone of the middle coat, that I begin to think that there must be some developmental rule why this should be; because if a uterus is found to have a so-called subserous fibroid and this is accompanied by other smaller ones they will. almost invariably be found on the peritoneal side of the central vascular zone of the middle coat. The same applies to the submucous fibroid; seldom does one see fibroids on both the inner and the outer side of the vascular zone of the middle coat simultaneously. The clinical pathology of the proposed classification of these tumours is interesting and shows a strong contrast in their behaviour.

No gynxecologist of any experience but must have seen a case of severe hæmorrhage trom a fibroid uterus, endangering life and often causing death, yet after hysterectomy or post mortem, on laying open the uterus, no point or punctured blood-vessel can be found anywhere to account for the hæmorrhage, the uterine mucous membrane over the tumour appearing merely congested. In conversation with Mr. Shattock, of the Royal College of Surgeons Museum, he very aptly described this hæmorrhage as "uterine epistaxis." This hæmorrhage or epistaxis in my experience is only caused by fibroids situated in the uterine wall on the inner side of the central vascular zone of the middle coat of the uterine wall, the salient factor not being that the fibroid is a so-called "submucous" fibroid, but that it is "internal" to the vascular zone in the middle coat of the uterus. How the hæmorrhage is caused can be britfly explained. The fibres of the middle coat outside the vascular zone and all the fibres of the outer coat when the fibroid has reached such a size that by their contraction they can compress the whole vascular circulation against the fibroid, cause an intense venous stasis of the mucosa, more especially over the tumour. And so we have established a læmorrhage very much like that which occurs in the stomach after gastroduodenostomy and other akdominal operations ; in other words, a true epistaxis which may or may not be fatal. This inner fibroid is also liable, in the event of a miscarriage occurring in the early months of an existing pregnancy, especially if the placental site be over the tumour, to become. 